\title{
Strategies to prevent anastomotic leakage after esophagectomy and gastric conduit reconstruction
}

\author{
Diana Vetter ${ }^{1} \cdot$ Christian A. Gutschow ${ }^{1}$ (I) \\ Received: 29 June 2020 / Accepted: 30 June 2020 / Published online: 10 July 2020 \\ (C) The Author(s) 2020
}

\begin{abstract}
Background Surgery remains the cornerstone of esophageal cancer treatment but is burdened with high procedure-related morbidity. Anastomotic leakage as the most important surgical complication after esophagectomy is a key indicator for quality in surgical outcome research.

Purpose The aim of this narrative review is to assess and summarize the current knowledge on prevention of anastomotic leakage after esophagectomy and to provide orientation for the reader in this challenging field of surgery.

Conclusions There are various strategies to reduce postoperative morbidity and to prevent anastomotic leakage after esophagectomy, including adequate patient selection and preparation, and many technical-surgical and anesthesiological details. The scientific evidence regarding those strategies is highly heterogeneous, ranging from expert's recommendations to randomized controlled trials. This review is intended to serve as an empirical guideline to improve the clinical management of patients undergoing esophagectomy with a special focus on anastomotic leakage prevention.
\end{abstract}

Keywords Esophagectomy $\cdot$ Anastomotic leakage $\cdot$ Prevention

\section{Introduction}

Despite significant progress in perioperative management, esophagectomy for cancer remains a procedure with relevant morbidity, even in high-volume centers [1,2]. The spectrum of postoperative morbidity after esophagectomy is broad, with pulmonary and anastomotic complications being the most common types [3-5].

Although different definitions and classifications [6] have been described, anastomotic leakage (AL) is a key indicator for surgical quality $[1,7]$ owing to its correlation with surgical expertise [8] and its tremendous impact on postoperative outcome. Sound surgical technique is key for proper anastomotic healing; however, AL rates $>20 \%$ have been reported even by renowned centers of expertise $[9,10]$. Moreover, there is no evidence that new technology such as minimally invasive and robotic-assisted techniques would reduce the risk for AL.

Christian A. Gutschow

christian.gutschow@usz.ch

1 Division Head Upper Gastrointestinal Surgery, Department of Visceral and Transplant Surgery, University Hospital Zurich, Rämistrasse 100, 8091 Zurich, Switzerland
Various strategies aim at prevention of AL, including proper patient selection, preparation and prehabilitation programs, techniques to improve and control vascularization of the gastric conduit, and many surgical and anesthesiological details. In this context, the aim of this narrative review was to summarize the spectrum of these strategies and to comment on their scientific evidence and clinical significance.

\section{Patient selection and preparation}

\section{Neoadjuvant treatments, comorbidity, and age}

Neoadjuvant chemotherapy or chemo-radiation followed by surgery has become the standard of care in the treatment of esophageal cancer $[11,12]$. However, a recent large retrospective European multicenter study revealed a significantly higher risk of postoperative complications including $\mathrm{AL}$ in cardiorespiratory comorbid patients after neoadjuvant chemo-radiation, but not after neoadjuvant chemotherapy [13, 14]. Consequently, neoadjuvant chemo-radiation should be employed with particular caution in patients with known respiratory comorbidity [15]. 
Numerous comorbidities are linked to increased AL risk such as obesity, heart failure, coronary artery disease, peripheral vascular disease, hypertension, steroids, diabetes mellitus, renal insufficiency, and tobacco use [16]. In addition, atrial fibrillation [17] and COPD [18] are known independent risk factors. Most comorbidities have a negative impact on microvascular perfusion, and it has been hypothesized that arteriosclerosis may play an important role in the etiology of $\mathrm{AL}$ [19]. Consequently, several retrospective cohort studies have confirmed an association between AL and loco-regional postcoeliac $[20,21]$ and aortic and coeliac trunk [22] calcifications. Moreover, others have evidenced an association between AL and supra-aortic and coronary arteriosclerosis [18], implying that general radiological arteriosclerosis scores may be useful to estimate the risk of AL [21, 23, 24].

Besides the abovementioned factors, age may play a major role in postoperative morbidity as older patients have more comorbidities and a reduced physiological resilience [25]. For example, older individuals have a higher probability of new-onset atrial fibrillation after esophagectomy [26], which is a known risk factor for pneumonia and AL. In addition, in patients $\geq 75$ years, the nutritional status is often impaired [27] and the sarcopenia rate is higher $[28,29]$. However, none of the prospective cohort studies comparing younger ( $<75$ years) and older $(\geq 75)$ cohorts found an association between age and postoperative morbidity or mortality $[27,30]$.

In summary, several secondary illnesses and comorbidities play a pivotal role in patient outcome after esophagectomy. In order to optimize preoperative assessment of esophageal cancer patients, prediction tools using readily available characteristics have been suggested recently [31]. Careful patient selection and thorough navigation through risks and benefits remains key for achieving optimal results.

\section{Preoperative nutrition}

Malnutrition is highly prevalent in patients with esophageal carcinoma and has been linked to a higher incidence of $\mathrm{AL}$ in GI-tract surgery [32]. Consequently, nutritional support prior to surgery is associated with a reduced complication rate after esophagectomy [33]. In this context, screening of the nutritional status in patients scheduled for esophagectomy following the ESPEN (European Society for Clinical Nutrition and Metabolism) criteria is highly recommended [34]. Most experts agree that preoperative nutritional support is indicated if body weight loss was $\geq 10-15 \%$ over the past 6 months, and in patients with a BMI $<18.5 \mathrm{~kg} / \mathrm{m}^{2}$ or a serum albumin $<$ $30 \mathrm{~g} / 1$ [34]. In addition, nutritionists should be involved to monitor protein and calorie intake and to assess the need for dietary supplements. In case of severe dysphagia, placement of an enteral feeding tube and preoperative nutritional support for a minimum of 7-14 days is recommended according to the ESPEN guidelines [35, 36].
Perioperative dietary supplementation with immunestimulating nutrients (omega-3 fatty acids, arginine, nucleotides) may reduce oxidative stress and inflammatory response. Correspondingly, perioperative immunonutrition was found to reduce postoperative morbidity in gastrointestinal cancer surgery in a systematic review of randomized controlled trials (RCTs) [37]. However, another recent metaanalysis of RCTs with a specific focus on esophagectomy did not confirm a positive effect of immunonutrition on $\mathrm{AL}$, overall morbidity, postoperative hospital stay, or immune indices such as C-reactive protein, interleukin-6, IL-8, and tumor necrosis factor- $\alpha$ [38]. Therefore, immunonutrition prior to esophageal cancer surgery remains a controversial issue.

\section{Prehabilitation}

Prehabilitation is a relatively new concept that entails a variety of preoperative measures to prepare patients for surgery. Prehabilitation is part of enhanced recovery after surgery (ERAS) protocols [39] and includes nutritional, physical, and psychological components. The physical component of prehabilitation programs entails inspiratory muscle training, aerobic exercise, and general strengthening activities. The effect of preoperative inspiratory muscle training on postoperative morbidity and AL rate remains controversial, although most research points towards a beneficial effect. The use of spirometers has been found to correlate positively with postoperative pulmonary morbidity [40], and two RCTs and one observational study have evidenced a reduction in severe pulmonary [41, 42] and overall complications [43] through perioperative inspiratory muscle training. However, other randomized studies could not confirm a benefit of inspiratory muscle training [44].

Likewise, aerobic exercises and strengthening activities during $>4$ weeks prior to esophagogastric surgery had a positive impact on preoperative fitness tests, an effect that sustained for 4-8 weeks after surgery [45]. Four RCTs on prehabilitation programs in gastroesophageal carcinoma are pending [46-49]. Interestingly, an RCT comparing the effect of prehabilitation with postoperative rehabilitation after colorectal cancer surgery evidenced that a 4-week prehabilitation program was even more effective than postoperative rehabilitation [50].

\section{Anesthesiological management and perioperative monitoring}

Anesthesiological measures focus on lung-protective ventilation, fluid management, and analgesia [51]. Restrictive perioperative fluid management has been recommended to reduce the rate of pulmonary complications and $\mathrm{AL}[51,52]$. However, excessive fluid restriction may cause hypovolemia, 
hypotension, and need for catecholamines, thus increasing the risk for ischemia and AL [6]. Similarly, epidural anesthesia has become an integral part of ERAS programs [53] and represents the standard of care for perioperative pain control in many centers. However, epidural analgesia causes perioperative hypotension in $20-76 \%$ of patients and has been directly associated with AL [54]. Therefore, standardized continuous monitoring of perioperative hemodynamics is pivotal to counterbalance potential drawbacks of esophagectomy-specific anesthesiological management [52].

\section{Surgical-technical aspects}

\section{Intrathoracic versus cervical anastomosis}

There is a long-standing debate whether the anastomosis after gastric pull-up procedure should be placed in the neck or intrathoracically. Most RCTs [55-58], retrospective cohort studies [2, 59, 60], and metaanalyses [21] show higher leak and recurrent nerve palsy rates but a reduced leak-associated morbidity after cervical anastomosis [4, 55, 60, 61]. The higher leak rate in cervical anastomoses might be caused by greater tension and placement in the gastric fundus (with potentially impaired vascular supply), whereas intrathoracic esophagogastrostomies are constructed under less longitudinal stress in a more distal and better-perfused gastric area [7, 62]. On the other hand, management of cervical AL is more straightforward and potentially less life threatening than intrathoracic AL. Interestingly however, a recent international survey among specialized surgeons has evidenced a strong tendency towards intrathoracic reconstructions [63], presumably owing to the substantial improvements regarding anastomotic leak management over the last years [64].

\section{Gastric tube formation}

Intestinal continuity after esophageal resection is typically restored using the whole stomach or a gastric tube. However, there is still considerable debate about the ideal type of conduit. The rationale for using a wide gastric tube or even the whole stomach was established more than 50 years ago by Levasseur and Couinaud [65] who showed that the intramural gastric vascular network originating from the left gastric artery connects the right and left gastroepiploic perfusion areas between antrum and fundus. This finding was later confirmed in autopsy studies [66, 67]. Accordingly, removal of the lesser curvature during gastric tubulization may induce ischemia of the upper part of the stomach and increase the risk for AL. With this in mind, others [68] have suggested to only remove the upper part of the greater curvature and to place the stapleline close to the lesser curvature in order to preserve as much intramural vascular network as possible. Jean-Marie Collard, from the same point of view, found that vascular and lymphatic denudation of the lesser curvature provides a similar lengthening effect without destruction of the intramural vascular network and advocated the whole stomach as best option for esophagogastric reconstruction with lower AL rate and superior function [67]. However, this concept has been challenged, arguing that a long and narrow gastric tube could reduce the incidence of AL owing to lower anastomotic tension. In summary, there is conflicting data in the literature regarding AL rate after narrow and wide gastric tube or whole stomach reconstructions. A recent meta-analysis found a similar AL rate, but a higher incidence of gastroesophageal reflux and thoracic stomach syndrome after whole stomach reconstruction [69]. Accordingly, most experts currently use a relatively broad $(4-5 \mathrm{~cm})$ gastric tube [70].

\section{Anastomotic technique}

Many different techniques have been devised for reconstruction after esophagectomy: (semi)mechanical or hand-sewn, linear-stapled, circular-stapled and double-stapled, end-toside, side-to-side, single-row, and double-row techniques. Moreover, the number of individual variations is legion owing to different suture materials and stapling devices, and the manifold individual technical steps taken by each surgeon. In addition, with the advent of minimally invasive esophagectomy, adjustments and modifications of existing techniques and even completely new designs have been developed [63].

A recent metaanalysis [71] showed similar AL rates in endto-side circular-stapled and side-to-side linear-stapled esophagogastrostomy. In contrast, AL rates after side-to-side linear-stapled esophagogastrostomy were lower compared with the end-to-side hand-sewn technique for cervical, but not for intrathoracic, anastomoses [72]. Consistently, both studies revealed a lower rate of anastomotic stenosis of sideto-side linear-stapled techniques, but the significance of these results remains doubtful owing to a lack of uniform definitions of AL and stricture.

In a large retrospective multicenter study including 966 patients that underwent minimally invasive thoracoscopiclaparoscopic esophagectomy, leakage rates after intrathoracic end-to-side double-stapling $(23.3 \%)$ and cervical end-to-side hand-sewn $(25.1 \%)$ techniques were significantly higher compared with intrathoracic side-to-side linear (15.6\%), end-toside purse-string (13.9\%), and cervical side-to-side linearstapled esophagogastrostomy (11.8\%) [7]. Multivariable analysis confirmed anastomotic technique as independent predictor of leakage. However, the authors concluded that the above results require cautious interpretation considering the long learning curve of minimally invasive esophagectomy. In conclusion, the scientific evidence on this topic remains weak and superiority of certain techniques in terms of leakage rate is questionable. Therefore, a surgeon's choice of a specific 
anastomotic design remains mainly based on personal experience rather than on solid scientific proof.

\section{Additional surgical measures}

Pedicled omental flaps have proven their usefulness in the management of complex thoracic and abdominal fistula. After esophagectomy, the upper part of the omentum along the gastric fundus can easily be wrapped around and sutured to the anastomosis [73]. This technical maneuver may be used in both cervical and intrathoracic anastomosis [74]. The wellperfused fatty tissue provides ample supply of nutrition and oxygen to the anastomotic area including secretion of vascular endothelial growth factor for enhanced angiogenesis and oxygenation [75]. In case of leakage, the omental flap may cover the defect by creating a contained situation that prevents free leakage to the mediastinum.

Numerous studies including a recent meta-analysis of randomized trials [76] have evaluated omental wrapping with positive results, and most specialist surgeons endorse this adjunct to improve healing of esophagogastric reconstructions.

With a similar rationale, many surgeons recommend to suture the mobilized pleura over the completed anastomosis [77]. "Pleural tenting" may be applied in combination with an omental wrap or as a single additional maneuver. However, to our best knowledge, this procedure has not been evaluated in comparative studies and remains a topic in need of further investigation.

Excessive tension at the anastomosis may occur in case of an incomplete vascular arcade, previous gastric surgery, or in very high cervical anastomoses. In these situations, additional length of the gastric tube can be gained by division of the peritoneal reflection of the hepatoduodenal ligament and by extensive duodenal mobilization (Kocher's maneuver). These techniques are particularly helpful if the distance between pylorus and hiatus remains too large after gastric mobilization [78]. In extreme cases, division of the branches of the right gastric artery, or even duodenal [79] or pyloric [80] diversion on a jejunal limb may generate extra mobility. Similarly, longitudinal [81] or circular [82] incision of the gastric serosa has been described to achieve additional length. However, we are not aware of any research on this topic and indications remain entirely based on individual experience.

\section{Intraoperative perfusion monitoring}

Assessment of the viability of the neo-esophagus usually relies on the surgeon's subjective evaluation. Typical signs of a healthy gastric tube include rosy-colored tissues, a pulsating vascular arcade, and active bleeding from the staple line or the upper part of the omentum. However, local ischemia at the tip of the gastric interponate is a frequent finding after gastric mobilization. Ischemia may depend on vascularization and other factors such as vasoconstriction, fluid management, catecholamine dosage, and the patient's hemodynamic situation. Therefore, a range of innovative tools for assessment of gastric tube viability has been developed over the last years: Laser Doppler flowmetry, near infrared spectroscopy, optical coherence tomography, and laser speckle contrast, infrared thermographic, fluorescence, and hyperspectral imaging [83]. Preliminary results of retro- and prospective cohort studies have shown promising results [84], and some of these tools have become commercially available. Perfusion monitoring is a promising technique, and a literature review has evidenced a significant benefit regarding AL rate [85]. Various questions remain albeit unanswered because many technical solutions still rely on subjective assessment, and no general agreement on perfusion parameters, normal values, thresholds, or quantitative validation has been established. Therefore, the current evidence supporting a routine intraoperative use of perfusion monitoring is still pending, and further research is required to fully explore its clinical potential.

\section{Ischemic conditioning}

Partial gastric devascularization prior to esophagectomy is a relatively new concept in esophageal surgery. The idea of ischemic conditioning is to optimize the gastric blood flow in preparation for later esophagectomy through preoperative selective occlusion of the left gastric \pm short gastric arteries. Arterial occlusion is accomplished by either surgical ligation or interventional embolization [86]. The resulting relative ischemia is expected to resolve via hemodynamic redistribution from the remaining vessels, thus avoiding ischemia during later reconstruction. In addition, gastric devascularization may lead to a demarcation of ischemic areas, facilitating the choice of the best location for anastomotic reconstruction [87]. Shortcomings of gastric conditioning include the need for additional resources, increased cost [88], and adhesion formation complicating subsequent gastric mobilization and lymphadenectomy $[89,90]$. Ischemic conditioning has been investigated in prospective and retrospective cohort studies including several RCTs [86]. Owing to divergent technical approaches, it is very difficult to draw conclusions. However, two recent meta-analyses of the current literature did not reveal a significant impact on AL rates [86, 88]. Therefore, many early advocates have abandoned ischemic conditioning in routine cases and reserve this option for high-risk patients that might benefit from a two-stage approach [91].

\section{Gastric decompression}

According to Laplace's law, the wall tension in a cylindrical vessel increases with greater radius and higher luminal pressure (wall tension $=$ pressure $\times$ radius). By applying basic physics to surgical practice, the intramural strain of a dilated 
gastric tube will be higher than in a properly drained interponate. Accordingly, insufficient postoperative gastric decompression may cause impaired blood perfusion, reduced oxygen supply, and a higher risk for AL or even gastric tube necrosis. Another potential benefit of gastric decompression is the prevention of regurgitation and aspiration. Therefore, most specialists rely on routine postoperative drainage of the conduit. On the other hand, prolonged gastric drainage may interfere with ERAS programs through delayed oral feeding with longer hospital stay and increased cost. In addition, nasogastric drains may cause discomfort and can also induce aspiration [92]. Therefore, some surgeons prefer percutaneous transcervical [93] or retrograde [94, 95] (via drainjejunostomy) conduit decompression. To untangle potential associations between postoperative conduit drainage and complications, numerous studies including several RCTs have been conducted with divergent results. A recent review on preoperative, early or late postoperative removal of gastric drains revealed no effect on AL rate, pulmonary complications, or mortality [96]. However, the current evidence remains weak owing to small sample sizes and the heterogeneity of the available evidence. In addition, comparability is further limited due to different techniques of luminal decompression, including single- or double-lumen (sump-)tubes with or without application of varying negative pressure.

\section{Preemptive vacuum therapy}

Treatment of AL has considerably progressed in recent years, and surgical revision has been largely replaced by interventional procedures. In addition to stent placement, endoluminal vacuum therapy (EVT) has become the treatment of choice in many specialized centers [64]. In EVT, a polyurethane sponge connected to a hose is brought to the anastomotic area via endoscopy. After vacuum application, the sponge drains the leakage cavity and removes secretions and necrosis, accomplishing an 80-90\% healing rate [97].

A novel idea is to use the EVT technology in a preemptive setting, with the aim of preventing AL and reducing postoperative morbidity. In a recent case series, early EVT in patients with anastomotic ischemia was effective in six of eight esophagectomy patients [98]. Likewise, in a porcine model, intraoperative application of EVT in esophagogastric anastomoses with intentional $1 \mathrm{~cm}$ defects resulted in complete healing [99]. Considering the high incidence of AL, we have recently implemented preemptive EVT ( $p E V T$ ) in patients undergoing esophagectomy and gastric tube reconstruction. Initial results were promising with a low leakage rate of $5 \%$ [100]. Since then, we have used pEVT with a persistently low AL rate in more than 80 cases. In the rare event of $\mathrm{AL}$, clinical courses were generally mild and without septic complications. Based on this positive experience, we have designed an international multicenter RCT (NCT04162860). The aim of this project is to prove whether $\mathrm{pEVT}$ may reduce $\mathrm{AL}$ rates and overall morbidity after minimally invasive esophagectomy.

\section{Comment}

Anastomotic leakage after esophagectomy is a severe complication with potentially devastating consequences. A wide range of measures to prevent $\mathrm{AL}$ has been suggested encompassing everything from adequate patient selection and prehabilitation over surgical training to many details of the operative procedure and perioperative management. Unfortunately, the quality of clinical research is highly variable and only few interventions are supported by strong evidence. Therefore, even in high-volume centers, both prevention and management of AL are mostly guided by empiric observation, pragmatism, and personal experience rather than based on solid scientific evidence.

The current lack of standardized definitions for key criteria of surgical quality outcome remains a major issue. As an example, there are more than 50 different definitions for anastomotic leakage [101-103] leaving much room for interpretation and impeding objective surgical outcome research. In this context, the definitions and classifications of complications after esophagectomy elaborated by the ECCG are a major step in the right direction [104] but may still take time to gain wide acceptance.

Since various comorbidities are clearly linked to increased $\mathrm{AL}$ incidence, selection of appropriate candidates for surgery might be the most efficient way to reduce postoperative morbidity. However, in many departments, functional evaluation of patients scheduled for esophagectomy is still arbitrary without clear guidelines. Therefore, both straightforward and accurate predictive tools are urgently needed. In this context, the introduction of simple nomograms using readily available clinical parameters to predict complication risks may gain acceptance in the future [31].

Surgical expertise, operative skills, and the use of stateof-the-art technique are the basic ingredients required for a successful esophageal cancer surgery program. Of note, minimally invasive esophagectomy has an extremely long learning curve of more than 100 cases until acceptable postoperative morbidity may be attained [8]. The effect of surgical learning on outcome has been shown based on operative time, overall morbidity and AL rate, percentage of textbook outcomes, and the number of resected lymph nodes [105-111]. Therefore, centralization of esophageal surgery in order to increase case numbers per center is pivotal to reduce the morbidity of this demanding procedure. In addition, learning curricula, proctoring programs, fellowships, and specialized courses with specific training in esophagectomy should be strongly encouraged. 
Code availability Not applicable.

Authors' contributions Christian Gutschow designed and drafted the manuscript.

Diana Vetter drafted and revised the manuscript.

Funding Information Open access funding provided by University of Zurich.

Data availability (data transparency) Not applicable.

\section{Compliance with ethical standards}

Conflict of interest Christian A. Gutschow and Diana Vetter have received an investor-initiated research grant from B. Braun Surgical, S.A., Barcelona, Spain.

Ethical approval This article does not contain any studies with human participants or animals performed by any of the authors.

Consent to participate Not applicable.

Consent for publication Not applicable.

Open Access This article is licensed under a Creative Commons Attribution 4.0 International License, which permits use, sharing, adaptation, distribution and reproduction in any medium or format, as long as you give appropriate credit to the original author(s) and the source, provide a link to the Creative Commons licence, and indicate if changes were made. The images or other third party material in this article are included in the article's Creative Commons licence, unless indicated otherwise in a credit line to the material. If material is not included in the article's Creative Commons licence and your intended use is not permitted by statutory regulation or exceeds the permitted use, you will need to obtain permission directly from the copyright holder. To view a copy of this licence, visit http://creativecommons.org/licenses/by/4.0/.

\section{References}

1. Low DE, Kuppusamy MK, Alderson D, Cecconello I, Chang AC, Darling G, Davies A, D'Journo XB, Gisbertz SS, Griffin SM, Hardwick R, Hoelscher A, Hofstetter W, Jobe B, Kitagawa Y, Law S, Mariette C, Maynard N, Morse CR, Nafteux P, Pera M, Pramesh CS, Puig S, Reynolds JV, Schroeder W, Smithers M, Wijnhoven BPL (2019) Benchmarking complications associated with esophagectomy. Ann Surg 269(2):291-298

2. Schmidt HM, Gisbertz SS, Moons J, Rouvelas I, Kauppi J, Brown A, Asti E, Luyer M, Lagarde SM, Berlth F, Philippron A, Bruns C, Hölscher A, Schneider PM, Raptis DA, Henegouwen MIB, Nafteux P, Nilsson M, Räsanen J, Palazzo F, Rosato E, Mercer S, Bonavina L, Nieuwenhuijzen G, Wijnhoven BPL, Schröder W, Pattyn P, Grimminger PP, Gutschow CA (2017) Defining benchmarks for transthoracic esophagectomy: a multicenter analysis of Total minimally invasive esophagectomy in low risk patients. Ann Surg 266(5):814-821

3. Fransen LFC, Berkelmans GHK, Asti E, van Berge Henegouwen MI, Berlth F, Bonavina L, Brown A, Bruns C, van Daele E, Gisbertz SS, Grimminger PP, Gutschow CA, Hannink G, Hölscher AH, Kauppi J, Lagarde SM, Mercer S, Moons J, Nafteux P, Nilsson M, Palazzo F, Pattyn P, Raptis DA, Räsanen
J, Rosato EL, Rouvelas I, Schmidt HM, Schneider PM, Schröder W, van der Sluis PC, Wijnhoven BPL, Nieuwenhuijzen GAP, Luyer MDP (2020) The effect of postoperative complications after minimally invasive esophagectomy on long-term survival: an international multicenter cohort study. Ann Surg

4. Markar S, Gronnier C, Duhamel A, Mabrut JY, Bail JP, Carrere N, Lefevre JH, Brigand C, Vaillant JC, Adham M, Msika S, Demartines N, Nakadi IE, Meunier B, Collet D, Mariette C, FREGAT (French Eso-Gastric Tumors) working group, FRENCH (Fédération de Recherche EN CHirurgie), and AFC (Association Française de Chirurgie) (2015) The impact of severe anastomotic leak on long-term survival and cancer recurrence after surgical resection for esophageal malignancy. Ann Surg 262(6):972-980

5. Booka E, Takeuchi H, Suda K, Fukuda K, Nakamura R, Wada N, Kawakubo H, Kitagawa Y (2018) Meta-analysis of the impact of postoperative complications on survival after oesophagectomy for cancer. BJS Open 2(5):276-284

6. Fabbi M, Hagens ERC, van Berge Henegouwen MI, Gisbertz SS (2020) Anastomotic leakage after esophagectomy for esophageal cancer: definitions, diagnostics, and treatment. Dis Esophagus

7. Schroder W, Raptis DA, Schmidt HM et al (2019) Anastomotic techniques and associated morbidity in Total minimally invasive transthoracic esophagectomy: results from the EsoBenchmark database. Ann Surg 270(5):820-826

8. van Workum F, Stenstra M, Berkelmans GHK et al (2019) Learning curve and associated morbidity of minimally invasive esophagectomy: a retrospective multicenter study. Ann Surg 269(1):88-94

9. van der Sluis PC, van der Horst S, May AM, Schippers C, Brosens LAA, Joore HCA, Kroese CC, Haj Mohammad N, Mook S, Vleggaar FP, Borel Rinkes IHM, Ruurda JP, van Hillegersberg R (2019) Robot-assisted minimally invasive thoracolaparoscopic esophagectomy versus open transthoracic esophagectomy for resectable esophageal cancer: a randomized controlled trial. Ann Surg 269(4):621-630

10. Straatman J, van der Wielen N, Cuesta MA, Daams F, Roig Garcia J, Bonavina L, Rosman C, van Berge Henegouwen MI, Gisbertz SS, van der Peet DL (2017) Minimally invasive versus open esophageal resection: three-year follow-up of the previously reported randomized controlled trial: the TIME trial. Ann Surg 266(2):232-236

11. van Hagen P, Hulshof MC, van Lanschot JJ et al (2012) Preoperative chemoradiotherapy for esophageal or junctional cancer. N Engl J Med 366(22):2074-2084

12. Al-Batran SE, Hofheinz RD, Pauligk C et al (2016) Histopathological regression after neoadjuvant docetaxel, oxaliplatin, fluorouracil, and leucovorin versus epirubicin, cisplatin, and fluorouracil or capecitabine in patients with resectable gastric or gastro-oesophageal junction adenocarcinoma (FLOT4AIO): results from the phase 2 part of a multicentre, open-label, randomised phase 2/3 trial. Lancet Oncol 17(12):1697-1708

13. Klevebro F, Friesland S, Hedman M, Tsai JA, Lindblad M, Rouvelas I, Lundell L, Nilsson M (2016) Neoadjuvant chemoradiotherapy may increase the risk of severe anastomotic complications after esophagectomy with cervical anastomosis. Langenbeck's Arch Surg 401(3):323-331

14. Klevebro F, Elliott JA, Slaman A, Vermeulen BD, Kamiya S, Rosman C, Gisbertz SS, Boshier PR, Reynolds JV, Rouvelas I, Hanna GB, van Berge Henegouwen MI, Markar SR (2019) Cardiorespiratory comorbidity and postoperative complications following esophagectomy: a European multicenter cohort study. Ann Surg Oncol 26(9):2864-2873

15. Nilsson M (2019) The combination of respiratory comorbidity and neoadjuvant chemoradiotherapy may double the risk of anastomotic leaks after esophagectomy: do we know enough to tailor 
neoadjuvant therapies, or take other preemptive measures in highrisk patients? Ann Surg Oncol 26(9):2660-2661

16. Kassis ES, Kosinski AS, Ross P Jr, Koppes KE, Donahue JM, Daniel VC (2013) Predictors of anastomotic leak after esophagectomy: an analysis of the society of thoracic surgeons general thoracic database. Ann Thorac Surg 96(6):1919-1926

17. Seesing MFJ, Scheijmans JCG, Borggreve AS, van Hillegersberg R, Ruurda JP (2018) The predictive value of new-onset atrial fibrillation on postoperative morbidity after esophagectomy. Dis Esophagus 31(11)

18. Borggreve AS, Goense L, van Rossum PSN, van Hillegersberg R, de Jong PA, Ruurda JP (2018) Generalized cardiovascular disease on a preoperative $\mathrm{CT}$ scan is predictive for anastomotic leakage after esophagectomy. Eur J Surg Oncol 44(5):587-593

19. Urschel JD (1995) Esophagogastrostomy anastomotic leaks complicating esophagectomy: a review. Am J Surg 169(6):634-640

20. Goense L, van Rossum PSN, Weijs TJ, van Det MJ, Nieuwenhuijzen GA, Luyer MD, van Leeuwen MS, van Hillegersberg R, Ruurda JP, Kouwenhoven EA (2016) Aortic calcification increases the risk of anastomotic leakage after IvorLewis esophagectomy. Ann Thorac Surg 102(1):247-252

21. van Rossum PSN, Haverkamp L, Verkooijen HM, van Leeuwen MS, van Hillegersberg R, Ruurda JP (2015) Calcification of arteries supplying the gastric tube: a new risk factor for anastomotic leakage after esophageal surgery. Radiology. 274(1):124-132

22. Chang DH, Brinkmann S, Smith L, Becker I, Schroeder W, Hoelscher A, Haneder S, Maintz D, Spiro JE (2018) Calcification score versus arterial stenosis grading: comparison of two CT-based methods for risk assessment of anastomotic leakage after esophagectomy and gastric pull-up. Ther Clin Risk Manag 14:721-727

23. Gondrie MJ, Mali WP, Jacobs PC, Oen AL, van der Graaf Y, Group PS (2010) Cardiovascular disease: prediction with ancillary aortic findings on chest CT scans in routine practice. Radiology. 257(2):549-559

24. Jacobs PC, Prokop M, Oen AL, van der Graaf Y, Grobbee DE, Mali WP (2010) Semiquantitative assessment of cardiovascular disease markers in multislice computed tomography of the chest: interobserver and intraobserver agreements. J Comput Assist Tomogr 34(2):279-284

25. Markar SR, Arya S, Karthikesalingam A, Hanna GB (2013) Technical factors that affect anastomotic integrity following esophagectomy: systematic review and meta-analysis. Ann Surg Oncol 20(13):4274-4281

26. Schizas D, Kosmopoulos M, Giannopoulos S, Giannopoulos S, Kokkinidis DG, Karampetsou N, Papanastasiou CA, Rouvelas I, Liakakos T (2019) Meta-analysis of risk factors and complications associated with atrial fibrillation after oesophagectomy. Br J Surg 106(5):534-547

27. Kanda M, Koike M, Tanaka C, Kobayashi D, Hayashi M, Yamada S, Nakayama G, Omae K, Kodera Y (2019) Feasibility of subtotal esophagectomy with systematic lymphadenectomy in selected elderly patients with esophageal cancer; a propensity score matching analysis. BMC Surg 19(1):143

28. Siegal SR, Dolan JP, Dewey EN, Guimaraes AR, Tieu BH, Schipper PH, Hunter JG (2018) Sarcopenia is not associated with morbidity, mortality, or recurrence after esophagectomy for cancer. Am J Surg 215(5):813-817

29. Deng HY, Zha P, Peng L, Hou L, Huang KL, Li XY (2019) Preoperative sarcopenia is a predictor of poor prognosis of esophageal cancer after esophagectomy: a comprehensive systematic review and meta-analysis. Dis Esophagus 32(3)

30. Baranov NS, van Workum F, van der Maas J, Kouwenhoven E, van Det M, van den Wildenberg FJH, Polat F, Nieuwenhuijzen GAP, Luyer MDP, Rosman C (2019) The influence of age on complications and overall survival after Ivor Lewis totally minimally invasive esophagectomy. J Gastrointest Surg 23(7): 1293-1300

31. Huang C, Yao H, Huang Q, Lu H, Xu M, Wu J (2020) A novel nomogram to predict the risk of anastomotic leakage in patients after oesophagectomy. BMC Surg 20(1):64

32. Yamano T, Yoshimura M, Kobayashi M, Beppu N, Hamanaka M, Babaya A, Tsukamoto K, Noda M, Matsubara N, Tomita N (2016) Malnutrition in rectal cancer patients receiving preoperative chemoradiotherapy is common and associated with treatment tolerability and anastomotic leakage. Int J Color Dis 31(4):877-884

33. Ligthart-Melis GC, Weijs PJ, te Boveldt ND et al (2013) Dietician-delivered intensive nutritional support is associated with a decrease in severe postoperative complications after surgery in patients with esophageal cancer. Dis Esophagus 26(6):587-593

34. Weimann A, Braga M, Carli F, Higashiguchi T, Hübner M, Klek S, Laviano A, Ljungqvist O, Lobo DN, Martindale R, Waitzberg DL, Bischoff SC, Singer P (2017) ESPEN guideline: clinical nutrition in surgery. Clin Nutr 36(3):623-650

35. Weimann A, Braga M, Harsanyi L, Laviano A, Ljungqvist O, Soeters P, DGEM (German Society for Nutritional Medicine), Jauch KW, Kemen M, Hiesmayr JM, Horbach T, Kuse ER, Vestweber KH, ESPEN (European Society for Parenteral and Enteral Nutrition) (2006) ESPEN guidelines on enteral nutrition: surgery including organ transplantation. Clin Nutr 25(2):224-244

36. Braga M, Ljungqvist $\mathrm{O}$, Soeters $\mathrm{P}$, Fearon $\mathrm{K}$, Weimann A, Bozzetti F, ESPEN (2009) ESPEN guidelines on parenteral nutrition: surgery. Clin Nutr 28(4):378-386

37. Zhang Y, Gu Y, Guo T, Li Y, Cai H (2012) Perioperative immunonutrition for gastrointestinal cancer: a systematic review of randomized controlled trials. Surg Oncol 21(2):e87-e95

38. Li XK, Zhou H, Xu Y, Cong ZZ, Wu WJ, Luo J, Jiang ZS, Shen Y (2020) Enteral immunonutrition versus enteral nutrition for patients undergoing oesophagectomy: a systematic review and meta-analysis. Interact Cardiovasc Thorac Surg 30(6):854-862

39. Low DE, Allum W, De Manzoni G et al (2019) Guidelines for perioperative care in esophagectomy: enhanced recovery after surgery (ERAS((R))) society recommendations. World J Surg 43(2): 299-330

40. Paul S, Altorki N (2014) Outcomes in the management of esophageal cancer. J Surg Oncol 110(5):599-610

41. van Adrichem EJ, Meulenbroek RL, Plukker JT, Groen H, van Weert E (2014) Comparison of two preoperative inspiratory muscle training programs to prevent pulmonary complications in patients undergoing esophagectomy: a randomized controlled pilot study. Ann Surg Oncol 21(7):2353-2360

42. Yamana I, Takeno S, Hashimoto T, Maki K, Shibata R, Shiwaku H, Shimaoka H, Shiota E, Yamashita Y (2015) Randomized controlled study to evaluate the efficacy of a preoperative respiratory rehabilitation program to prevent postoperative pulmonary complications after esophagectomy. Dig Surg 32(5):331-337

43. Akiyama Y, Iwaya T, Endo F, Shioi Y, Kumagai M, Takahara T, Otsuka K, Nitta H, Koeda K, Mizuno M, Kimura Y, Suzuki K, Sasaki A (2017) Effectiveness of intervention with a perioperative multidisciplinary support team for radical esophagectomy. Support Care Cancer 25(12):3733-3739

44. Valkenet K, Trappenburg JCA, Ruurda JP, Guinan EM, Reynolds JV, Nafteux P, Fontaine M, Rodrigo HE, van der Peet DL, Hania SW, Sosef MN, Willms J, Rosman C, Pieters H, Scheepers JJG, Faber T, Kouwenhoven EA, Tinselboer M, Räsänen J, Ryynänen H, Gosselink R, van Hillegersberg R, Backx FJG (2018) Multicentre randomized clinical trial of inspiratory muscle training versus usual care before surgery for oesophageal cancer. Br J Surg 105(5):502-511

45. Minnella EM, Awasthi R, Loiselle SE, Agnihotram RV, Ferri LE, Carli F (2018) Effect of exercise and nutrition prehabilitation on 
functional capacity in esophagogastric cancer surgery: a randomized clinical trial. JAMA Surg 153(12):1081-1089

46. Le Roy B, Pereira B, Bouteloup C et al (2016) Effect of prehabilitation in gastro-oesophageal adenocarcinoma: study protocol of a multicentric, randomised, control trial-the PREHAB study. BMJ Open 6(12):e012876

47. Pfirrmann D, Tug S, Brosteanu O, Mehdorn M, Busse M, Grimminger PP, Lordick F, Glatz T, Hoeppner J, Lang H, Simon P, Gockel I (2017) Internet-based perioperative exercise program in patients with Barrett's carcinoma scheduled for esophagectomy [iPEP - study] a prospective randomized-controlled trial. BMC Cancer 17(1):413

48. Allen S, Brown V, Prabhu P, Scott M, Rockall T, Preston S, Sultan J (2018) A randomised controlled trial to assess whether prehabilitation improves fitness in patients undergoing neoadjuvant treatment prior to oesophagogastric cancer surgery: study protocol. BMJ Open 8(12):e023190

49. Sheill G, Guinan E, O'Neill L et al (2020) Preoperative exercise to improve fitness in patients undergoing complex surgery for cancer of the lung or oesophagus (PRE-HIIT): protocol for a randomized controlled trial. BMC Cancer 20(1):321

50. Gillis C, Li C, Lee L, Awasthi R, Augustin B, Gamsa A, Liberman AS, Stein B, Charlebois P, Feldman LS, Carli F (2014) Prehabilitation versus rehabilitation: a randomized control trial in patients undergoing colorectal resection for cancer. Anesthesiology. 121(5):937-947

51. Durkin C, Schisler T, Lohser J (2017) Current trends in anesthesia for esophagectomy. Curr Opin Anaesthesiol 30(1):30-35

52. Klevebro F, Boshier PR, Low DE (2019) Application of standardized hemodynamic protocols within enhanced recovery after surgery programs to improve outcomes associated with anastomotic leak and conduit necrosis in patients undergoing esophagectomy. J Thorac Dis. 11(Suppl 5):S692-S701

53. Findlay JM, Gillies RS, Millo J, Sgromo B, Marshall RE, Maynard ND (2014) Enhanced recovery for esophagectomy: a systematic review and evidence-based guidelines. Ann Surg 259(3):413-431

54. Fumagalli U, Melis A, Balazova J, Lascari V, Morenghi E, Rosati R (2016) Intra-operative hypotensive episodes may be associated with post-operative esophageal anastomotic leak. Updat Surg 68(2): 185-190

55. Chasseray VM, Kiroff GK, Buard JL, Launois B (1989) Cervical or thoracic anastomosis for esophagectomy for carcinoma. Surg Gynecol Obstet 169(1):55-62

56. Walther B, Johansson J, Johnsson F, Von Holstein CS, Zilling T (2003) Cervical or thoracic anastomosis after esophageal resection and gastric tube reconstruction: a prospective randomized trial comparing sutured neck anastomosis with stapled intrathoracic anastomosis. Ann Surg 238(6):803-812 discussion 812-804

57. Okuyama M, Motoyama S, Suzuki H, Saito R, Maruyama K, Ogawa J (2007) Hand-sewn cervical anastomosis versus stapled intrathoracic anastomosis after esophagectomy for middle or lower thoracic esophageal cancer: a prospective randomized controlled study. Surg Today 37(11):947-952

58. Ribet M, Debrueres B, Lecomte-Houcke M (1992) Resection for advanced cancer of the thoracic esophagus: cervical or thoracic anastomosis? Late results of a prospective randomized study. J Thorac Cardiovasc Surg 103(4):784-789

59. Liu YJ, Fan J, He HH, Zhu SS, Chen QL, Cao RH (2018) Anastomotic leakage after intrathoracic versus cervical oesophagogastric anastomosis for oesophageal carcinoma in Chinese population: a retrospective cohort study. BMJ Open 8(9):e 021025

60. Gooszen JAH, Goense L, Gisbertz SS, Ruurda JP, van Hillegersberg R, van Berge Henegouwen MI (2018) Intrathoracic versus cervical anastomosis and predictors of anastomotic leakage after oesophagectomy for cancer. Br J Surg 105(5):552-560

61. Biere SS, Maas KW, Cuesta MA, van der Peet DL (2011) Cervical or thoracic anastomosis after esophagectomy for cancer: a systematic review and meta-analysis. Dig Surg 28(1):29-35

62. Bludau M, Vallbohmer D, Gutschow C, Holscher AH, Schroder W (2008) Quantitative measurement of gastric mucosal microcirculation using a combined laser Doppler flowmeter and spectrophotometer. Dis Esophagus 21(7):668-672

63. Haverkamp L, Seesing MF, Ruurda JP, Boone J, Hillegersberg RV (2017) Worldwide trends in surgical techniques in the treatment of esophageal and gastroesophageal junction cancer. Dis Esophagus 30(1):1-7

64. Valli PV, Mertens JC, Kroger A et al (2018) Stent-over-sponge (SOS): a novel technique complementing endosponge therapy for foregut leaks and perforations. Endoscopy. 50(2):148-153

65. Levasseur JC, Couinaud C. [Study of the distribution of gastric arteries. 2d part: surgical incidences]. J Chir (Paris) 1968;95(2): $161-176$

66. Pierie JP, de Graaf PW, van Vroonhoven TJ, Obertop H (1998) The vascularization of a gastric tube as a substitute for the esophagus is affected by its diameter. Dis Esophagus 11(4):231-235

67. Collard JM, Tinton N, Malaise J, Romagnoli R, Otte JB, Kestens PJ (1995) Esophageal replacement: gastric tube or whole stomach? Ann Thorac Surg 60(2):261-266 discussion 267

68. Liebermann-Meffert DM, Meier R, Siewert JR (1992) Vascular anatomy of the gastric tube used for esophageal reconstruction. Ann Thorac Surg 54(6):1110-1115

69. Zhang W, Yu D, Peng J, Xu J, Wei Y (2017) Gastric-tube versus whole-stomach esophagectomy for esophageal cancer: a systematic review and meta-analysis. PLoS One 12(3):e0173416

70. Lameris W, Eshuis WJ, Cuesta MA, Gisbertz SS, van Berge Henegouwen MI (2019) Optimal mobilization of the stomach and the best place in the gastric tube for intrathoracic anastomosis. J Thorac Dis. 11(Suppl 5):S743-S749

71. Zhou D, Liu QX, Deng XF, Min JX, Dai JG (2015) Comparison of two different mechanical esophagogastric anastomosis in esophageal cancer patients: a meta-analysis. J Cardiothorac Surg 10:67

72. Deng XF, Liu QX, Zhou D, Min JX, Dai JG (2015) Hand-sewn vs linearly stapled esophagogastric anastomosis for esophageal cancer: a meta-analysis. World J Gastroenterol 21(15):4757-4764

73. Ohwada S, Ogawa T, Kawate S, Kawashima Y, Takeyoshi I, Koyama T, Kasahara M, Sunose Y, Tomizawa N, Morishita Y (2000) Omentoplasty for cervical esophagogastrostomy following radical esophagectomy with three-field dissection. Hepatogastroenterology. 47(35):1305-1309

74. Wilkins E Esophageal surgery. Second edition. Churchill Livingstone, Philadelphia

75. Zhang QX, Magovern CJ, Mack CA, Budenbender KT, Ko W, Rosengart TK (1997) Vascular endothelial growth factor is the major angiogenic factor in omentum: mechanism of the omentum-mediated angiogenesis. J Surg Res 67(2):147-154

76. Yuan Y, Zeng X, Hu Y, Xie T, Zhao Y (2014) Omentoplasty for oesophagogastrostomy after oesophagectomy. Cochrane Database Syst Rev 10:CD008446

77. Asteriou C, Barbetakis N, Lalountas M, Kleontas A, Tsilikas C (2011) Modified pleural tenting for prevention of anastomotic leak after Ivor Lewis esophagogastrectomy. Ann Surg Oncol 18(13): 3737-3742

78. H A (1990) Surgery for cancer of the esophagus. Williams \& Wilkins, Baltimore

79. Yoshida N, Baba Y, Hiyoshi Y, Shigaki H, Kurashige J, Sakamoto Y, Miyamoto Y, Iwatsuki M, Ishimoto T, Kosumi K, Sugihara H, Harada K, Tokunaga R, Izumi D, Watanabe M, Baba H (2016) Duration of smoking cessation and postoperative morbidity after 
esophagectomy for esophageal cancer: how long should patients stop smoking before surgery? World J Surg 40(1):142-147

80. Yamagishi M, Ikeda N, Yonemoto T (1970) An isoperistaltic gastric tube. New method of esophageal replacement. Arch Surg 100(6):689-692

81. Sugimachi K, Yaita A, Ueo H, Natsuda Y, Inokuchi K (1980) A safer and more reliable operative technique for esophageal reconstruction using a gastric tube. Am J Surg 140(3):471-474

82. Endo MHF, Hamano K, Nakamura M, Takasaki T, Nakayama K (1975) Radical operation for the carcinoma of the esophagus, antethoracic esophagogastrostomy by some modified techniques. Chir Gastroenterol 9:295-297

83. Kohler H, Jansen-Winkeln B, Chalopin C, Gockel I (2019) Hyperspectral imaging as a new optical method for the measurement of gastric conduit perfusion. Dis Esophagus 32(10):1

84. Zehetner J, DeMeester SR, Alicuben ET et al (2015) Intraoperative assessment of perfusion of the gastric graft and correlation with anastomotic leaks after esophagectomy. Ann Surg 262(1):74-78

85. Slooter MD, Eshuis WJ, Cuesta MA, Gisbertz SS, van Berge Henegouwen MI (2019) Fluorescent imaging using indocyanine green during esophagectomy to prevent surgical morbidity: a systematic review and meta-analysis. J Thorac Dis 11(Suppl 5): S755-S765

86. Kamarajah SK, Boyle C, Bundred JR, Tan BH (2020) Critical appraisal of gastric conduit ischaemic conditioning (GIC) prior to oesophagectomy: a systematic review and meta-analysis. Int $\mathbf{J}$ Surg 77:77-82

87. Schroder W, Holscher AH, Bludau M, Vallbohmer D, Bollschweiler E, Gutschow C (2010) Ivor-Lewis esophagectomy with and without laparoscopic conditioning of the gastric conduit. World J Surg 34(4):738-743

88. Mingol-Navarro F, Ballester-Pla N, Jimenez-Rosellon R (2019) Ischaemic conditioning of the stomach previous to esophageal surgery. J Thorac Dis. 11(Suppl 5):S663-S674

89. Berrisford RG, Veeramootoo D, Parameswaran R, Krishnadas R, Wajed SA (2009) Laparoscopic ischaemic conditioning of the stomach may reduce gastric-conduit morbidity following total minimally invasive oesophagectomy. Eur J Cardiothorac Surg 36(5):888-893 discussion 893

90. Varela E, Reavis KM, Hinojosa MW, Nguyen N (2008) Laparoscopic gastric ischemic conditioning prior to esophagogastrectomy: technique and review. Surg Innov 15(2): 132-135

91. Bartella I, Brinkmann S, Fuchs H et al (2020) Two-stage hybrid Ivor-Lewis esophagectomy as surgical strategy to reduce postoperative morbidity for high-risk patients. Surg Endosc

92. Nelson R, Edwards S, Tse B (2007) Prophylactic nasogastric decompression after abdominal surgery. Cochrane Database Syst Rev 3:CD004929

93. Schuchert MJ, Pettiford BL, Landreneau JP, Waxman J, Kilic A, Santos RS, Kent MS, el-Sherif A, Abbas G, Luketich JD, Landreneau RJ (2008) Transcervical gastric tube drainage facilitates patient mobility and reduces the risk of pulmonary complications after esophagectomy. J Gastrointest Surg 12(9):1479-1484

94. Sato T, Takayama T, So K, Murayama I (2007) Is retention of a nasogastric tube after esophagectomy a risk factor for postoperative respiratory tract infection? J Infect Chemother 13(2):109-113

95. Puri V, Hu Y, Guthrie T, Crabtree TD, Kreisel D, Krupnick AS, Patterson GA, Meyers BF (2011) Retrograde jejunogastric decompression after esophagectomy is superior to nasogastric drainage. Ann Thorac Surg 92(2):499-503

96. Weijs TJ, Kumagai K, Berkelmans GH, Nieuwenhuijzen GA, Nilsson M, Luyer MD (2017) Nasogastric decompression following esophagectomy: a systematic literature review and meta-analysis. Dis Esophagus 30(3):1-8
97. Berlth F, Bludau M, Plum PS, Herbold T, Christ H, Alakus H, Kleinert R, Bruns CJ, Hölscher AH, Chon SH (2019) Selfexpanding metal stents versus endoscopic vacuum therapy in anastomotic leak treatment after oncologic gastroesophageal surgery. J Gastrointest Surg 23(1):67-75

98. Neumann PA, Mennigen R, Palmes D, Senninger N, Vowinkel T, Laukoetter MG (2017) Pre-emptive endoscopic vacuum therapy for treatment of anastomotic ischemia after esophageal resections. Endoscopy. 49(5):498-503

99. Scott RB, Ritter LA, Shada AL, Feldman SH, Kleiner DE (2017) Endoluminal vacuum therapy for Ivor Lewis anastomotic leaks: a pilot study in a swine model. Clin Transl Sci 10(1):35-41

100. Gubler C, Vetter D, Schmidt HM et al (2019) Preemptive endoluminal vacuum therapy to reduce anastomotic leakage after esophagectomy: a game-changing approach? Dis Esophagus 32(7)

101. Price TN, Nichols FC, Harmsen WS, Allen MS, Cassivi SD, Wigle DA, Shen KR, Deschamps C (2013) A comprehensive review of anastomotic technique in 432 esophagectomies. Ann Thorac Surg 95(4):1154-1160 discussion 1160-1151

102. Bruce J, Krukowski ZH, Al-Khairy G, Russell EM, Park KG (2001) Systematic review of the definition and measurement of anastomotic leak after gastrointestinal surgery. Br J Surg 88(9): $1157-1168$

103. Lerut T, Coosemans W, Decker G, De Leyn P, Nafteux P, van Raemdonck D (2002) Anastomotic complications after esophagectomy. Dig Surg 19(2):92-98

104. Low DE, Alderson D, Cecconello I, Chang AC, Darling GE, D Journo XB, Griffin SM, Hölscher AH, Hofstetter WL, Jobe BA, Kitagawa Y, Kucharczuk JC, Law SYK, Lerut TE, Maynard N, Pera M, Peters JH, Pramesh CS, Reynolds JV, Smithers BM, van Lanschot JJB (2015) International consensus on standardization of data collection for complications associated with esophagectomy: esophagectomy complications consensus group (ECCG). Ann Surg 262(2):286-294

105. Tapias LF, Morse CR (2014) Minimally invasive Ivor Lewis esophagectomy: description of a learning curve. J Am Coll Surg 218(6):1130-1140

106. Mu JW, Gao SG, Xue Q, Mao YS, Wang DL, Zhao J, Gao YS, Huang JF, He J (2015) Updated experiences with minimally invasive McKeown esophagectomy for esophageal cancer. World $\mathrm{J}$ Gastroenterol 21(45):12873-12881

107. Zhu ZY, Yong X, Luo RJ, Wang YZ (2018) Clinical analysis of minimally invasive McKeown esophagectomy in a single center by a single medical group. J Zhejiang Univ Sci B 19(9):718-725

108. Sarkaria IS, Rizk NP, Grosser R, Goldman D, Finley DJ, Ghanie A, Sima CS, Bains MS, Adusumilli PS, Rusch VW, Jones DR (2016) Attaining proficiency in robotic-assisted minimally invasive esophagectomy while maximizing safety during procedure development. Innovations (Phila) 11(4):268-273

109. Park S, Hyun K, Lee HJ, Park IK, Kim YT, Kang CH (2018) A study of the learning curve for robotic oesophagectomy for oesophageal cancer. Eur J Cardiothorac Surg 53(4):862-870

110. Hernandez JM, Dimou F, Weber J, Almhanna K, Hoffe S, Shridhar R, Karl R, Meredith K (2013) Defining the learning curve for robotic-assisted esophagogastrectomy. J Gastrointest Surg 17(8):1346-1351

111. Zhang H, Chen L, Wang Z, Zheng Y, Geng Y, Wang F, Liu D, He A, Ma L, Yuan Y, Wang Y (2018) The learning curve for robotic McKeown esophagectomy in patients with esophageal cancer. Ann Thorac Surg 105(4):1024-1030

Publisher's note Springer Nature remains neutral with regard to jurisdictional claims in published maps and institutional affiliations. 